\title{
Sense of achievement: Initial evaluation of an Integrated Engineering Design cornerstone module
}

\author{
Emanuela Tilley and John E Mitchell \\ University College London, e.tilley, j.mitchell@ucl.ac.uk
}

\begin{abstract}
Pressure from industry, professional bodies and students for a reform to the curriculum and delivery style of engineering education in the United Kingdom has been mounting for a number of years. Although there have been many excellent individual initiatives, developments that span a whole school or faculty, those encompassing a number of disciplines and departments are rare. This paper describes the curriculum development and evaluation of a year 1 module for the new Integrated Engineering Programme, which spans across the UCL faculty of engineering sciences in the UK. It describes the motivation for change, some of the approaches adopted and the achievements documented by the students.
\end{abstract}

Index Terms - Engineering Education, Integrated Curriculum, Problem/Project-based Learning, Evaluation

\section{INTRODUCTION}

Over the past three years, the Faculty of Engineering Science at University College London (UCL) has undertaken a critical review and reform of the curriculum for the majority of its undergraduate engineering programmes. This is in part due to an overwhelming sense of flux attributed to the state of engineering education within the United Kingdom. There is a wealth of reports reviewing and offering acute assessments of the suitability of engineering graduates for roles in industry with common themes being very well rehearsed. For example, "Universities must do more to ensure students acquire the generic transferable skills they will need in their future career - including communication skills, self management and business awareness - alongside the core academic content of university courses. The teaching of these skills should not be viewed as a discretionary 'add-on"' [1]. This is echoed in a key message of the Royal Academy of Engineering report [2] "University engineering courses must provide students with the range of knowledge and innovative problem-solving skills to work effectively in industry as well as motivating students to become engineers on graduation".

The reforms aimed to create a distinctive programme featuring a connected-curriculum and drawing on the excellent research-base of UCL. A founding premise was that although a strong disciplinary foundation was vital, modern engineering problems do not respect these disciplinary boundaries. Therefore, modern engineering graduates must be able to work in multi-disciplinary teams on interdisciplinary problems. They must have a strong basis in fundamental mathematics and engineering science, but must also have highly developed problem solving and communication skills. In addition, the modern engineer should understand the context of the problems they address, appreciating the ethical, societal and financial connotations of their design decisions. To produce such engineers, an integrated curriculum that develops all these areas simultaneously is required. The programme that resulted has been named the Integrated Engineering Programme (IEP) and the first students to embark on this programme, a cohort of nearly 700, started in September 2014.

The programmes in the UCL Engineering Faculty cover a broad range of disciplines: Biochemical, Biomedical, Chemical, Civil, Electronic and Electrical, Mechanical Engineering and Computer Science. The reforms keep direct entry into, and exit from, each of the disciplines but introduce a common structure that enables regular crosscutting activities. The activities take place from the first week of term and are repeated at regular intervals throughout the programme. They take different forms and aim to provide different types of experiences to students depending on the stages of their development. However, they all share a common purpose; providing opportunities for students to develop a broad understanding of engineering problems and disciplines through practical activities. A high-level overview of the structure is shown in Figure 1.

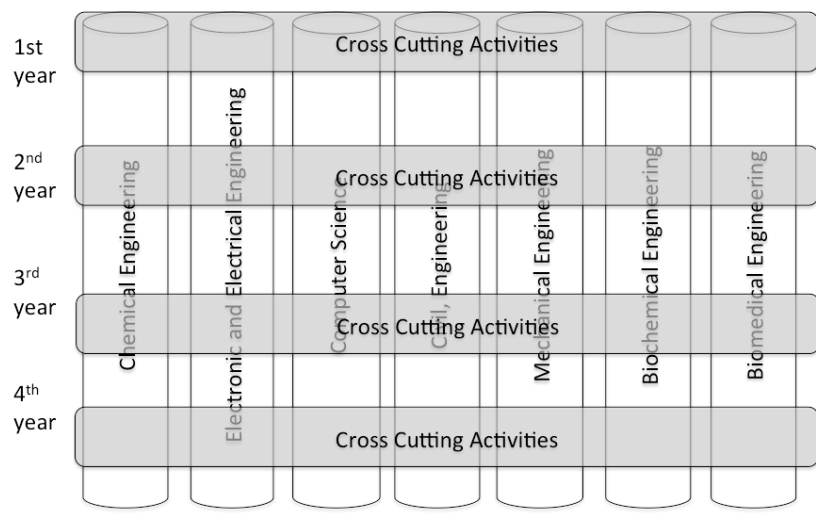

FIGURE 1

OVERVIEW OF INTEGRATED ENGINEERING PROGRAMME STRUCTURE 
Academic best practice dictates that investments into a formal review process are made to resolve if the design and delivery of a new course curriculum has achieved its desired outcomes and to highlight key factors that have both positively and negatively contributed. This paper is simply a snapshot, a work in progress piece, which fits within a considerably wider evaluation study currently being undertaken for the first year of UCL's IEP. It aims to provide a critical review of the new cornerstone engineering design module, Integrated Engineering Design, aptly referred to as IE Design or the Challenges module, from the perspective of the enrolled students, via their individual feedback and reflections. The Challenges module places engineering design at its core and aligns its pedagogic practice to the well-known and established principles of problem/project-based learning (PBL/PjBL). The students' evaluation of the team project that consumed much of the first half of their first term at UCL Engineering has provided a rich data set, which has also assisted in formulating a greater sense of achievement on behalf of both the students and academics involved.

\section{IEP IMPACT STUDY: ESTABLISHING THE STUDENT VOICE}

A longitudinal study is currently being established to look at the impact of the programme on students enrolled in the Integrated Engineering Programme (IEP) at University College London, a mixed discipline cohort of students from across the faculty, as well as the quality of its organization and delivery. An important piece of evidence for the IEP impact study is a short on-line survey completed by the newly enrolled year 1 students at the beginning of their first term at UCL, prior to the start of classes. The primary purpose of the survey was to understand the initial perceptions of the students upon embarking on their engineering education at UCL. Moreover, the results of which can be used to inform refinements in the IEP, as well discipline specific, curricular design. The survey was also designed so that it could be completed by the IEP students at the start of each academic year throughout their degree. The motivation is to understand if any changes have occurred in the student perception of their educational experiences throughout their chosen degree and the IEP. Recently, the survey has been given to current final year students who have not been enrolled in the IEP, to allow for a comparison of data upon the graduation of the first IEP cohort.

The first set of questions in the survey asked the students to ascertain the future opportunities they seek as engineering graduates before considering their own learning expectations and anticipating the most enjoyable as well as beneficial educational experiences. The middle section of the survey sets out a series of statements to understand the student's intentions for choosing UCL as their educational institution and reasons for choosing to study engineering. Finally, the survey culminates with a single question asking the students to reflect on their confidence levels on a series of skills, which are considered as essential to anyone pursuing a career in engineering.

Initial findings suggest that upon graduation nearly a quarter of the UCL Engineering IEP cohort is seeking a career that suit them personally and provide a sense of happiness. Moreover, ten percent of students would like to positively contribute to the world around them. An innate sense of continuous learning and civic consideration in the role of an engineer has also been relayed by ten percent of the students, as they seek opportunities to expand their own knowledge, skills and attitudes in engineering and beyond. A separate ten percent of the cohort is driven by the intrigue, excitement and challenges that are associated with working on real-world engineering projects.

The opportunities sought after by first year UCL engineering students are supported by the learning expectations they have communicated for their time spent as undergraduates. Building technical knowledge of the chosen discipline and solving real engineering problems have naturalized as being the most significant. Ten percent of students expect to learn how to think like an engineer, build knowledge and collect information for their future career and improve communication, presentation and technical writing skills. The results of the survey convey prevalence in these three areas over their expectancy to improve individual team-working skills, mathematic and science knowledge, design and making skills and creativity. Students also believe these to be more important than achieving a top grade.

Results of the questions seeking the student's opinion on the most beneficial and then separately, the most enjoyable education experiences in their development as a professional engineer, support the changes brought on by the IEP. The results in Table 1 give an ordered mandate to the educational experiences that the students perceive will be most beneficial. In the second column, the most enjoyable experiences as anticipated by the students surveyed, are also provided.

A simple insight that could be drawn from the results of the student survey is the high value and expectation of the students to benefit and enjoy authentic educational experiences whilst exploring team-based problem solving opportunities and developing individual professional skills. Even before their first class, students are of the opinion that lectures, where the conveying of technical information and content occurs between academic staff and their passive student audience, will be beneficial to their own development but not necessarily enjoyable. The independent learning experience has gathered a similar impression. Interestingly, engineering labs and learning from fellow students are viewed by those surveyed as being enjoyable but rather less beneficial. The results even suggest that students feel as though engineering labs would be more enjoyable than the authentic engineering experiences supported by industry and community involvement. From this, it is evident that the students will enjoy the hands-on experience that comes with working on engineering projects. 
The authenticity in this style of learning is something that the Integrated Engineering Design module hopes to appropriate and assimilate to the engineering 'Challenges' that comprise its syllabus. As the module is augmented by industry and community involvement, the provision for students to benefit and experience enjoyment whilst participating in the presented authentic engineering opportunities can be realised. Furthermore, the enjoyment that comes with learning from fellow students is reported as higher than the perceived benefits. Because this cornerstone module of the IEP first year is rooted in principles of teambased learning, impetus to help increase the student's perception on the value of learning from their student colleagues is emphatically provided.

TABLE I

IMPACT SURVEY YR1 STUDENT DATA

\begin{tabular}{lll}
\hline Pedagogical experience & $\begin{array}{l}\text { Most } \\
\text { Beneficial } \\
(\%)\end{array}$ & $\begin{array}{l}\text { Most } \\
\text { Enjoyable } \\
(\%)\end{array}$ \\
\hline $\begin{array}{l}\text { Engineering team-based problem } \\
\text { solving }\end{array}$ & 26 & 24 \\
$\begin{array}{l}\text { Activities and experiences to } \\
\text { develop professional skills (e.g. }\end{array}$ & 18 & 17 \\
leadership, team-working, & & \\
communication) & 12 & 5 \\
Lectures taught by academic & & \\
staff & 11 & 21 \\
Engineering labs & 8 & 5 \\
Independent learning & 4 & 8 \\
Learning from fellow students & 2 & 1 \\
Revising for and sitting exams & 2 & \\
\hline
\end{tabular}

\section{INTEGRATED ENGINEERING DESIGN: UCL ENGINEERING'S CORNERSTONE MODULE}

The IE Design module is intended to give the students an opportunity to put their learning into practice by working in an interdisciplinary, problem/project-based learning, industry linked and design focused environment. At its core, is the deliberate attempt to make use of and explore the creative and stimulating aspects of design as practiced by 'real' engineers and computer scientists in industry and the professional skills needed to be successful in the enticing and highly competitive working world. In many ways the insights, presented by the voice of the students through the initial IEP Impact survey, give evidence to many of the empirical reasons for introducing radical changes to the undergraduate curriculum, particularly to the addition of the team based, IE Design PBL/PjBL module.

There was a clear desire to increase the practical application of engineering in the early stages of all degree programmes. The opportunities afforded to the UCL engineering students across the seven undergraduate disciplines varied markedly and it was thought that the IEP would be able to restore some balance of the student learning experience across the faculty. Problem/project- based activities have long been documented as an effective means in increasing student motivation through the integration of 'real' problems [3]. These authentic activities give each student the opportunity to put into practice their technical and theoretical knowledge while at the same time enhancing a wide range of professional skills. Such skills are being increasingly emphasized by industry as key to graduate employability. To best develop this range of skills, we believe that students must engage in authentic learning experiences, which allow them to enhance both their theoretical knowledge but also their skills in problemsolving, communication, team-work and design that are vital in engineering. These types of experiences are hard to create within a lecture theatre, must be developed early, not left to final year projects and must be in context if accusations of 'add-ons' [1] are to be avoided.

The basic structure of the Term 1 IE Design module consists of two 5-week 'Challenges', which have the students working in teams of mixed cohorts. The themes for the ill-defined problems for the two Challenges are linked to such global challenges as sustainability and health. The learning objectives of the second Challenge build from those of the first. The first has its basis in problem-based learning, whilst the second has a higher level of specification that aligns well with the principles of project-based learning [5]. The technical focus and level of difficulty also increases from the first to the second as the students in the first 5weeks of term are considered to be bright, inquisitive, enthusiastic, high-achieving students well versed in STEM subjects, but who do not have much technical knowledge of their chosen engineering discipline. Upon completion of the IE Design module, an initial sense of autonomy in the students is expected as they take responsibility for your own learning through your individual and team based experiences within this problem-based learning environment.

Both Challenges are presented to the teams of students with a human-centred design approach to problem solving in order for them to take into consideration stakeholder and user needs [6]. They are implored to identify and define the requirements, constraints and design parameters of their project, whilst engaging in research-led activities and selfstudy through enquiry-based learning. They are taught to explore the process of design and engineering thinking, whilst applying mathematics and engineering analysis to the development and creation of an integrated engineering solution. There is a focus in the first Challenge on the use of creativity to generate concepts, exercise critical thinking, implement a methodology to compare ideas and use engineering judgment to choose a final solution. Whereas, the second Challenge affords the student an opportunity to demonstrate knowledge and understanding of the equipment, materials and processes employed in the design, production and testing of engineering systems, including specialized test and measurement equipment relevant to your chosen engineering discipline. The module and the associate Challenges are supported through the integrated and aligned 
syllabuses of the other three modules during the first term. These modules comprise mathematical modelling and analysis, design and professional skills and a technical introduction specific to their chosen discipline. Results of the evaluation survey for the module, completed by the students at the end of the term, indicate that all of the intended learning outcomes discussed here were successfully achieved by $50 \%$ of the cohort. This is considered a fair result, however improvements can be made. More pleasing, perhaps, is the relatively high percentage of students who acknowledged their learning to:

- Take responsibility for your own learning experience within a project based learning environment $(72 \%)$;

- Work effectively in a team (68\%); and

- Engage in research activities and self-study through asking questions and general inquiry (67\%).

\section{INITIAL ACHIEVEMENTS: IE DESIGN MODULE EVALUATION VIA STUDENT REFLECTIONS AND FEEDBACK}

The following section of this paper sets out to evaluate five key pedagogical experiences within the first of the two 5week Challenges. A short description is provided along with student feedback collected either in person, via email / Moodle (i.e. online module intranet) discussion boards or as posted in individual e-portfolio reflective writing coursework. Following each is an attempt to share the observations and reflections associated with each, from the perspective of students and academics involved, whilst attempting to formulate a sense of achievement on behalf of the students but also in terms of the module aims.

Aspect of IE Design Module \#1: Two-hour kick-off lecture and demonstration to full 700 student cohort. The lecture provided an introduction to the authentic real world sustainable energy problem the students will be working on in teams for one of ten assigned countries/communities around the world.

Student Feedback - Example \#1: "Thank you, having the chance to work on projects like these is very important to me. My life goal is to make a difference in the world whether big or small with the skills I gain from my degree here at UCL. I want to go back to Mozambique and do what I can to help the community I grew up in."

Student Feedback - Example \#2: "Felt like a lot of information at once - unsure of how much of the project contributes to our final grade and how far we are judged considering we have not really learnt anything of our respective disciplines at present. Wasn't aware of individual responsibilities for specific parts of the project. The grouping of eng. students was exciting and the project was well 'promoted' in the presentation - while daunting it feels non-the-less intriguing!"
The start of IE Design was initiated by a gathering of all 700 students in a kick-off lecture presented by the module director and relevant guest speakers. The two-hour event was organized and performed with the intention of inspiring the students to unreservedly take on and consider genuine sustainable energy problems for communities all over the world. It was important to consider the significant role engineers can have in creating and delivering real solutions and to embark on collaboration as a unique and effective way of learning. Inspirational examples of graduate engineers using their degrees to contribute solutions to global issues under the theme of sustainability and sustainable energy helped to deliver UCL Engineering's vision of Change the World; to change the world you need to be taught differently.

Students in the audience participated via online Turning Point technology led discussion polls and microphone supported question time, whilst feedback from the students that followed included a standing ovation and individual words of gratitude from many students. Additional feedback also acknowledged that for most being sat in a 700-person lecture theatre on their first day of classes was enthralling and uplifting, which gave them a sense of community, whilst for a small minority of students, it was overwhelming and lead them to disengage and feel a sense of worry. Additionally, it was realised that many of the practical information of the module was missed in such an atmosphere, thus more time and consideration was given to provide support via online channels and in subsequent design workshops.

Aspect of IE Design Module \#2: Design Review Meetings 15 minute formative assessment sessions for student teams to present coursework progress and get feedback from their academic leaders.

Student Feedback - Example \#3: "The following are the lessons I learned from our meeting with our academic leader:

- To not give information we cannot back up will facts and correct statistics.

- We need to do more research into the stakeholders (people affected by this project e.g. miming companies) of this project and how are they affected.

- We need to understand what sustainability is properly.

- $\quad$ Our arguments need to be more technical and very detailed.

- We need to find out answers to some very detailed questions like, 'How much do these people earn?' and 'How much energy is used in schools, by females, males and children?'.

- If we don't know something we should not assume but be honest and say that 'we do not know etc.... and we need to find out'." 
At two timely milestones within the 5-week Challenge, meetings were scheduled between each of the student teams and their academic leader. The meetings occurred informally during the workshops, where the academic leader would move around from team to team in the two-hour regularly scheduled timeslot, sitting and conversing with the students. Students were given guidance notes ahead of the meetings, in order for them to understand how they were meant to prepare for the meeting and what work needed to be completed in advance. The meetings themselves were set out in a working-life setting, which engineers are often called upon by a director or an external client to disclose details of their project work as well as an update on progress. Students were asked to prepare and deliver a short presentation summarizing their work at the start of the meeting and then, the academic would follow up with their feedback and questions. An expectation was set up with the students that they were to lead the meeting and that they should make the most of the meeting with the academic to clarify any misunderstandings or uncertainties they were encountering.

These meetings also served as a means of encouraging an ipsative learning environment [4], in which both the students and academics could engage. Many students feel a real sense of achievement when progress is acknowledged and these meetings gave academics an opportunity to provide that for their students. Interim coursework deadlines associated with these meetings also supported the students in their own time management. The weekly deadlines associated with the meetings and the individual components of the project work wasn't appreciated by the students as many regarded the anxiety and pressure to deliver work as too overwhelming in their first 5-weeks at UCL. This was quickly dismissed when students realised that much of the work had been completed in advance of their final submission deadline before the half term break. It is important to note that the schedule for submission of work is not as controlled in the second Challenge, giving the students a varying approach to time management of both individual and team elements of coursework. This was a strategic design of the module syllabus, as it was felt that autonomy of ones own learning can only be realised if given a variety of experiences to explore and evaluate.

The content of the student reflection lends support to the notion that in PBL, facilitation can help the students to explore their research and go into further depth with their ideas and concepts than if left without. Often the facilitator will expect the student to formulate an opinion, gather evidence to provide a technical argument and make decisions on matters that perhaps they would not have, if not challenged to do so. Lastly, it is important that the students understand that failure can be beneficial to their learning experience. Often this realization doesn't occur unless the academic reassures them and guides them through it. The realization made by the student that he/she cannot make assumptions without finding evidence to support it, is an important one. It isn't until students are faced with having to explain their own logic, estimations and assumptions that they come to realise the importance of this.

Aspect of IE Design Module \#3: Exploration of the design process and developing a student's understanding of engineering thinking and methodology. Introducing external consultants to the students as subject experts as part of the teaching team for the module.

Student Reflection- Example \#4: "I have learnt that the design process is a useful tool to use on projects as it helps you get organized for the project and increases your chances of success."

Student Reflection - Example \#5: "Our initial step was to research into what the actual problem is. We investigated and researched further into the problem to find out about all aspects of the energy problem. We looked at all aspects of the problem, not just the technical bits, and then started to think about some good and viable solutions for the problem. The research helped us come up with ideas. The research was tough though, sometimes I had no idea what I was reading, but we had many study sessions together and meetings to brainstorm ideas and then we started coming up with some real diverse solutions."

Student Reflection - Example \#6: "The most dominant professional skill that we used, was in-depth research in our topic. All of us researched a lot. We started asking a lot of questions to the energy experts. I am good at asking questions! We had a big variety of ideas and possible solutions to each design, which was interesting to discuss. The other important skill was that of presentation by which we made our solution understandable by our teachers and classmates."

The focus on the process of design and a clear intention to have the students explore what engineering thinking is, has helped to give them a sense of self-efficacy. As relayed by the student in the Example 4, understanding (even briefly) the stages in the design process has helped many teams get through the first 5-week Challenge successfully. Because the process itself is often iterative by nature, which may require the need to restart or rethink work that has already been completed, it can often be frustrating. The frustration is often amplified when working in a team. Giving the students a sense of organization through the creative process is something that many appreciated.

Many would attest to the stereotypical portrayal of engineers who often skip the creative thinking or ideation phase of the design process and start at the testing and implementation of their first idea. Accordingly, engineering students are seemingly no different. Feedback from academic and industry advisors have indicated that students struggle with affording themselves enough time to properly investigate and research the problem, the stakeholders and their needs as well as the state of the art that currently exists 
in their technical fields. The first of the two Challenges, forced the students to complete an exhaustive research and self-study of the cultural and technical challenges surrounding their assigned country, the people that experience the problem and the policies, strategies and technologies currently available. The student reflections in Example 5 and 6 have also touched on how time dedicated to self-study in these areas has contributed to the quality and quantity of ideas generated by the team. The authenticity of both the real life problem and the engineering project compel the students to further their own learning, which often results in a greater sense of achievement.

Aspect of IE Design Module \#4: Team-working and leadership experiences and opportunities, both technical and adaptive in nature.

Student Reflection - Example \#7: "I think this course is very exciting as it encourages us to be open minded to other student's ideas and enhances the social interaction between students from different engineering disciplines to share their ideas and work as a team to provide a real world problem solution. Although, my team experience in this Challenge wasn't ideal, I think I know now that it is important to talk about responsibilities and even to have the group appoint a leader, even when we are not asked to. It is better if everyone takes on an individual role. It is easier to organize, less chaos around deadlines and things get done better too."

Students are initially introduced to the fundamental elements of engineering design and thinking, how to work successfully in teams, effective communication and professional practices, in their Term 1 Design and Professional Skills module as an effective strategy to address the growing need for high performing engineering graduates with a well-rounded set of skills. In this way, the PBL environment is being strengthened to give students the tools and vocabulary to help them identify, fully explore, utilize and develop their natural talents and personal strengths throughout their engineering education prior to graduation. Through the team-working environment associated with the Challenges, students develop a heightened awareness of each other's potential to contribute to the team goals that in turn also helps them deal with and possibly limit the occurrence of problems associated with leadership, communication, time management, assignment of roles, and division of responsibility often experienced when working in teams. Additionally, addressing this level of self-awareness, students build mutual respect and the IEP aims to produce graduates that are more easily attuned to the diversity and inclusive engineering practices that essentially are founded on respect.

Aspect of the IE Design \#5: Blending learning elements (i.e. online content, learning plans, videos and e-Portfolios) within the IE Design module as well as clarity of deadlines, assessment and organisation to support the independent learning experience of each student.

Student Reflection - Example \#8: "Make it clear EXACTLY WHAT we're doing and WHEN, so it doesn't stress us out, especially at this early stage. So we can kick start our studies properly. The digital portfolio is a good idea, but should have used wordpress instead."

Student Reflection - Example \#9: "Making a video of our team's engineering design solution was better than doing a final presentation. It was fun, but it also took a lot more time to do a good job. The challenge was trying to explain what our final idea was and at the same time explain why we think it will work. It wasn't easy but thankfully there was someone in the team that likes doing creative stuff like this. I am proud to have something to show for our hard work."

The assessment of the students work was primarily based on the collation of a digital portfolio, which included both the team's collaborative work as well individual aspects from each student. To help assist the students with the division of work and to pre-empt the occurrence of non-contributing students amongst each of the teams, individual deadlines were set ahead of the team deadlines so that all students participate in the generation of the team's final portfolio. Although the software chosen, Mahara's MyPortfolio, may not have been to all students liking, the feedback from many, as indicated in Example 9, gave an appreciation for having them create a body of work that they can keep digitally and use to show others easily. As deadlines were relatively frequent, students stressed that there be one strategy for submission, with consistency of deadline dates/times. Recently, this has been reinforced implementing an online calendar of deadlines and workshop schedule for the IE Design module, which each student can personalize and embed into their own personal UCL timetable.

Students have been very vocal in their positive experience and personal sense of achievement upon completion of the final solution video. The first Challenge culminated with each student team creating a three to four minute video showcasing their team's sustainable energy design solution. They were asked to present their final solution, whilst also giving some time to tell the audience about the problem they are addressing and the needs of the stakeholders they've targeted in their project. It is also important that they describe their team design brief including their design criteria. The video also required them to formulate a technical argument as for why they believe their final solution met the design criteria they set out with evidence on how it is technically feasible, economically viable and socially/environmentally desirable. Not only was this aspect of the Challenge a rewarding one in terms of the final assessment, but there was a separate prize competition, which involved the inclusion of votes from members of the wider UCL community and our industry partners, which contributed a bit of fun. 


\section{SUMMARY}

This paper gives a brief overview of a major element of the year 1 Integrated Engineering Programme, a revamped undergraduate curriculum review project at UCL. The aim of the IE Design module is to enhance the student experience by introducing problem/project-based activities that allow students to put the basis for engineering design and thinking into context and practice. This is primarily done through team-based learning. It draws on the broad research base of UCL to create a connected-curriculum with a number of multi-disciplinary elements to students entering their first year. Individual reflections and feedback from the students who have recently embarked on the programme have served to give a real sense of their personal achievement. These are shared by academic staff and have been used as a means to evaluate the achievements of the cornerstone module. The data collected have helped to inform improvements to the module for future years, whilst highlighting a group of students who are keen to support future developments.

\section{REFERENCES}

[1] CBI Education and skills survey "Emerging stronger: the value of education and skills in turbulent times". CBI, 2009

[2] Royal Academic of Engineering. "Educating Engineers for the 21st Century", 2007

[3] M. Savin-Baden, and K. Wilkie, "Challenging Research in ProblemBased Learning". Society for Research into Higher Education and Open University Press, 2004

[4] Dweck, Carol S. "Mindset: The New Psychology of Success", New York: Random House, Inc, 2006.

[5] Savin Badin, M., Howell Major, C. "Foundations of Problem-based Learning, The Society for Research into Higher Education". Maidenhead: Open University Press, McGraw-Hill Education, 2004.

[6] IDEO. Human-Centred Design Toolkit, $2^{\text {nd }}$ Edition [internet]. Seattle Bill \& Melinda Gates Foundation. [cited 2014 July]. Available from: http://d1r3w4d5z5a88i.cloudfront.net/assets/toolkit/IDEO.org HCD ToolKit English-5fef26ba5fa5761a3b021057d1d4a851.pdf 